\title{
Annotation Guideline No. 7: Guidelines for annotation of narrative structure
}

\author{
Mats Wirén, Adam Ek and Anna Kasaty
}

\author{
01.15 .20
}

Article DOI: 10.22148/001c.11772

Journal ISSN: 2371-4549

Cite: Mats Wirén, Adam Ek and Anna Kasaty, "Annotation Guideline No. 7: Guidelines for annotation of narrative structure," Journal of Cultural Analytics. January 15, 2020. doi: 10.22148/001c.11772

\section{Rationale}

\section{Background}

Analysis of narrative structure can be said to answer the question "Who tells what, and how?". The first part of the question thus concerns aspects such as who is narrating, whether it is a character in the story or not, and if it is a first-person or third-person narrator. The second part is related to the story and its basic elements: characters and events, and how the sequence of events forms a plot. The third part concerns how the narrative text is constructed: ordering of the events, the perspective from which the story is seen, how much information the narrator has access to, etc.

The key part of our annotation scheme is related to the "who?", in other words, keeping track of who is doing the telling (showing, speaking), and to whom. To this end, our annotation scheme is grounded in the basic levels of narrative transmission: author-reader (highest level), narrator-narratee (intermediate level) and

\footnotetext{
${ }^{1}$ Manfred Jahn, "N2. The narratological framework", in Narratology: A guide to the theory of narrative, http://www.uni-koeln.de/ ${ }^{\sim}$ ame02/pppn (accessed September 30, 2018). Compare also the classification of "narration" (which is about the "who?"), "story" ("what?") and "text" ("how"?) in Shlomith Rimmon-Kenan, Narrative fiction: Contemporary poetics (New York: Routledge, 2002).
} 
character-character (lowest level). ${ }^{2}$ Typically, works of literary fiction consist of alternations between the second and third of these levels: narration and fictional dialogue. As for narration, we annotate voice, which corresponds to the narrator's relationship to the story, and specifically whether the narrator is ever present in the story or not. The most detailed part of our annotation concerns the dialogue, however, for which we keep track of turns, lines, speakers and addressees.

Our annotation of the "what?" is rather rudimentary. We have a notion of scene which is meant to capture a coherent set of events and characters at a particular time and place, but no means of ordering sequences of scenes timewise or causally, and hence no notion of plot. Also, only characters that take part in fictional dialogue become part of the annotation.

Our annotation of the "how?" is also relatively rudimentary. We annotate focalisation, that is, the perspective from which the narrative is seen and specifically how much information the narrator has access to. Furthermore, we annotate narrative levels in the sense of stories within stories by using embeddings within the intermediate level of narrative transmission.

Our emphasis of the "who?" no doubt reflects the fact that we have approached the problem of narrative structure from linguistics. In particular, given the apparent resemblances between fictional dialogue and everyday conversation, it makes sense to apply linguistic models in the analysis of the former. ${ }^{3}$ Suitable models that have been mentioned in the literature include speech-act theory and Conversation Analysis, but computational methods for the study of dialogue may also be useful. In contrast, the language of higher narrative-transmission levels can only "create an illusion, an effect, a semblance of mimesis," ${ }^{4}$ which means that the role of linguistic analysis is less straightforward.

In developing our annotation scheme, we have used the following criteria as guiding principles:

- Simplicity and readability. We have opted for a simple annotation scheme whose result should be easy to read together with the original texts. To this end, we use embedded (in-line) annotation in the original text.

- Hierarchical tagset. To increase inter-annotator agreement, we use a hierarchical tagset with mutually exclusive tag categories in the same layers.

\footnotetext{
${ }^{2}$ Manfred Jahn, "N2.4. Narrative Levels", in Narratology: A guide to the theory of narrative, http: //www.uni-koeln.de/ ame02/pppn (accessed September 30, 2018).

${ }^{3}$ As pointed out by Aino Koivisto and Elise Nykänen, "Introduction: Approaches to fictional dialogue", in International Journal of Literary Linguistics 5, no. 2 (2016), http://www.ijll.uni-mainz.de/ index.php/ijll/article/view/56 (accessed September 30, 2018).

${ }^{4}$ Shlomith Rimmon-Kenan, Narrative fiction: Contemporary poetics (New York: Routledge, 2002), 109.
} 
- Minimal interpretation. Ideally, we would like an annotation which represents as objectively as possible the basic events, the characters involved and the discourse levels through which the narrative is transmitted, without undue subjective interpretation. This is arguably the most difficult principle to attain, however.

- Relation to linguistic annotation. We assume that a machine-learning model for predicting narrative structure will be based on annotation of both the narrative and linguistic structures of the text. The latter might build on what is produced by a standard automatic linguistic-analysis pipeline, involving, for example, sentence segmentation, tokenisation, part-of-speech tagging, named-entity recognition, syntactic parsing and co-reference resolution. ${ }^{5}$ In contrast to narrative annotation, we consider linguistic annotation to be a means and not a goal in itself, and therefore do not include discussion of this here.

\section{Overview of annotation layers}

Our tagset is hierarchically structured in four annotation layers, ordered by an inclusion relation. The top layer encodes voice, using the tags $\langle$ VOICE_1 $>$ and $<$ VOICE_3 $>$ that correspond to whether the narrator is present in the story or not, respectively. These are the opening tags; the corresponding closing tags are written with a slash, </VOICE_1 $>$ and $</$ VOICE_3 $>$ (and similarly for other tags throughout). The second layer encodes focalisation, that is, the perspective from which the narrative is seen and how much information the narrator has access to. It includes the tags $\langle$ FOC_UNR $>$, $\langle$ FOC_INT $>$ and $<$ FOC_EXT $>$, corresponding to unrestricted, internal and external focalisation, respectively. The fact that the annotation of focalisation is included in that of voice means that a change of voice requires resetting focalisation, even though the value of the focalisation may not change.

A focalisation includes one or more scenes in the third layer, $<$ SCENE $>$, each of which is a coherent set of events at a particular interval in time and place, with a more or less constant set of characters. A scene typically consists of alternations between narration and dialogue, annotated using $<$ NARRATOR $>$ and $<$ CHARACTERS $>$, but may also contain $<$ AUTHOR $>$. In addition, these types of discourses may be embedded in each other (to be detailed below).

\footnotetext{
${ }^{5}$ For example, Stanford CoreNLP (for English), https://stanfordnlp.github.io/CoreNLP/ (accessed September 30, 2018); efselab (for Swedish), https://github.com/robertostling/efselab (accessed September 30, 2018).
} 
A characters' discourse, <CHARACTERS $>$, consists of one or more turns, each of which is associated with one speaker (or a chorus of several speakers) and one or more addressees (who may vary). Thus, whereas the speaker (or set of speakers) is immutable throughout a turn, this does not necessarily hold for the addressee(s). Finally, each turn consists of one or more lines, each of which is associated with one speaker (or a chorus of several speakers) and one addressee (or a set of addressees). In addition, a line consists of one or more utterances, that is, sentences or fragments typically distinguished by full stops in the text. Utterances are not part of the annotation, however. Note that only lines are tagged with speaker(s) and addressee(s), and that there is no notion of opening or closing tags in this case. Note also that we make a difference between addressees and listeners: addressees are the recipients of lines, whereas listeners overhear lines without being recipients. We only annotate addressees. In sum, a characters' discourse is a sequence of turns uninterrupted by narrator's discourses (unless they are embedded). A description of the layers and discourse levels is shown in Table 1.

\begin{tabular}{|c|c|c|}
\hline Layer & Tag & Description \\
\hline 1 & $<$ VOICE_1 $>,\langle$ VOICE_3 $>$ & Narrator's presence in the story (yes, no) \\
\hline 2 & $\langle$ FOC_UNR $\rangle,\langle$ FOC_INT $\rangle,\langle$ FOC_EXT $\rangle$ & $\begin{array}{l}\text { Perspective of the narrator (unrestricted, } \\
\text { internal, external) }\end{array}$ \\
\hline 3 & $<$ SCENE $>$ & $\begin{array}{l}\text { Coherent set of events and characters at } \\
\text { particular interval of time and place }\end{array}$ \\
\hline 4.1 & $<$ AUTHOR $>$ & Narrative transmission: Highest level \\
\hline 4.2 & $<$ NARRATOR $>$ & Narrative transmission: Intermediate level \\
\hline 4.3 & $<$ CHARACTERS $>$ & Narrative transmission: Lowest level \\
\hline 4.3 .1 & $<$ TURN $>$ & Turn: One or several lines \\
\hline 4.3 .2 & $<$ Speaker-Addressee $>$ & $\begin{array}{l}\text { Line: One or several utterances. Tagged only } \\
\text { with speaker(s) and addressee(s) }\end{array}$ \\
\hline
\end{tabular}

Table 1. Hierarchical structure of the annotation scheme.

We use a deliberately simple criterion for delimiting the scope of a narrator's discourse, namely, letting each paragraph that begins with narration correspond to one narrator's discourse by enclosing it with opening and closing tags $(<$ NARRATOR $>$ and $<$ /NARRATOR $>$ ). As for dialogue, each turn is often put in a paragraph of its own in fictional works. But when we have a sequence of turns, whether each line is in a paragraph of its own or not, we let the entire sequence be enclosed by the corresponding opening and closing tags, that is, $<$ CHARACTERS $>$ and $</$ CHARACTERS $>$. 


\section{Discourse levels}

\section{Introduction}

We assume that a text in its entirety can be divided into occurrences of the following three discourse levels: ${ }^{6}$

- Highest level: Transmission from the author to a (typically) imagined, but explicitly referred reader of the work (for an example, see Section Transmission across levels). We refer to this as author's discourse.

- Intermediate level: Transmission from a narrator to a narratee. The latter can be visible or invisible, but is distinct from (the imagined) reader of the work. We refer to this as narrator's discourse.

- Lowest level: Transmission between characters in the story in the form of dialogue, whether direct or indirect discourse. ${ }^{7}$ We refer to this as characters' discourse. The dialogue is typically spoken, but we also take soliloquy and interior monologue to be possible types of characters' discourse. ${ }^{8}$

Assuming that transmission between author and reader is the exception in fiction, a narrative typically consists of passages alternating between the two lower levels. $^{9}$

To annotate discourses in the three levels, we use opening and closing tags indicating both the type of speaker and addressee at the respective level, namely, <AUTHOR-READER>, <NARRATOR-NARRATEE $>$ and $<$ CHARACTERS-CHARACTERS $>$. For convenience, and when there is no ambiguity, we may abbreviate $<$ NARRATOR-NARRATEE $>$ as $<$ NARRATOR $>$ and $<$ CHARACTERS-CHARACTERS $>$ as $<$ CHARACTERS $>$. An example text with alternating narrator's and characters' discourses is shown in Example (1). ${ }^{10}$ (Note that this author uses neither dashes nor quotation marks, but only paragraph breaks, to indicate turns.)

Melissa had her camera on the table and occasionally lifted it to take a photograph, laughing self-deprecatingly about being a 'work addict'. She

\footnotetext{
${ }^{6}$ Manfred Jahn, "N2.3. Narrative communication", in Narratology: A guide to the theory of narrative, http://www.uni-koeln.de/ ame02/pppn (accessed September 30, 2018).

${ }^{7}$ Manfred Jahn, "N4", in Narratology: A guide to the theory of narrative, http://www.uni-koeln.de/ ame02/pppn (accessed September 30, 2018).

${ }^{8}$ For a listing of different representations of speech, see Shlomith Rimmon-Kenan, Narrative fiction: Contemporary poetics (New York: Routledge, 2002).

${ }^{9}$ As stated in Lubomír Doležel, Narrative Modes in Czech Literature (Toronto: University of Toronto Press, 1973), quoted in Manfred Jahn, "N8.1", in Narratology: A guide to the theory of narrative, http://www.uni-koeln.de/ ${ }^{\sim}$ ame02/pppn (accessed September 30, 2018): "Every narrative text T is a concatenation and alternation of [narrator's discourse] and [characters' discourse]".

${ }^{10}$ From Sally Rooney, Conversations with Friends (London: Faber \& Faber, 2017), 4-5.
} 
lit a cigarette and tipped the ash into a kitschy-looking glass ashtray. The house didn't smell of smoke at all and I wondered if she usually smoked in there or not.

I made some new friends, she said.

Her husband was in the kitchen doorway. He held up his hand to acknowledge us and the dog started yelping and whining and running around in circles.

This is Frances, said Melissa. And this is Bobbi. They're poets.

He took a bottle of beer out of the fridge and opened it on the countertop.

Come and sit with us, Melissa said.

Yeah, I'd love to, he said, but I should try and get some sleep before this flight. Example (2) shows how (1) would be annotated for narrator's and characters' discourses. The latter includes turns, whereas lines are introduced further below. Vertical space corresponds to alternations of discourse level for readability.

\section{(2) $<$ NARRATOR>}

Melissa had her camera on the table and occasionally lifted it to take a photograph, laughing self-deprecatingly about being a 'work addict'. She lit a cigarette and tipped the ash into a kitschy-looking glass ashtray. The house didn't smell of smoke at all and I wondered if she usually smoked in there or not.

$<$ /NARRATOR $>$

$<$ CHARACTERS $>$

$<$ TURN $>$

I made some new friends, she said.

$</$ TURN $>$

$</$ CHARACTERS $>$

$<$ NARRATOR $>$

Her husband was in the kitchen doorway. He held up his hand to acknowledge us and the dog started yelping and whining and running around in circles.

$<$ NARRATOR $>$

$<$ CHARACTERS $>$

$<$ TURN $>$ 
This is Frances, said Melissa. And this is Bobbi. They're poets.

$</$ TURN $>$

$</$ CHARACTERS $>$

$<$ NARRATOR $>$

He took a bottle of beer out of the fridge and opened it on the countertop.

$<$ /NARRATOR $>$

$<$ CHARACTERS $>$

$<$ TURN $>$

Come and sit with us, Melissa said.

Yeah, I'd love to, he said, but I should try and get some sleep before this flight.

$</$ TURN $>$

$</$ CHARACTERS $>$

\section{Characters' discourses}

Whereas narrator's discourses capture narrations in the text, characters' discourses corresponds to fictional dialogues between characters. A characters' discourse consists of one or more turns, each of which consists of one or more lines as defined above. A characters' discourse is thus a sequence of turns uninterrupted by narrator's discourses.

To represent transmission between characters, we annotate each line with its speaker and addressee, as in example (3). ${ }^{11}$ Specifically, we assume that a turn has a single speaker, but that different lines within a turn may have different addressees. Also, a speaker may address more than one character simultaneously, which means that one line can have several addressees. We only annotate the intended recipient(s) of the utterance as addressees, whereas listeners who only overhear a line are not annotated.

(3) <CHARACTERS $>$

$<$ TURN>

We're all on the same side here, Derek said. <Derek-ALL>

${ }^{11}$ From Sally Rooney, Conversations with Friends (London: Faber \& Faber, 2017), 112. 
Nick, you're an oppressive white male, you back me up. <Derek-Nick $>$

$</$ TURN $>$

$<$ TURN $>$

I actually quite agree with Bobbi, said Nick. Oppressive though I certainly am. $<$ Nick -Derek $>$

$</$ TURN $>$

$</$ CHARACTERS $>$

The first turn is divided into two lines since there is a change in addressees. The second turn consists of one line which consists of two utterances.

Note that we do not have opening and closing tags that surround lines, but just a speaker-addressee tag at the end of each line. The scope of the speakeraddressee tag is the current line.

What we refer to as a line consists of a line proper, which is what is actually spoken by the character, and optionally a speech-verb construction, which indicates who the speaker (and possibly the addressee) is. Example (4) shows a line proper with the direct speech of the officer, whereas Example (5) shows the speech-verb construction that identifies the speaker.

(4) "That was the first story,"

(5) "said the officer,"

We have chosen to include the speech-verb construction in the line tag to avoid cluttering the annotation, and because these constructions follow a predictable pattern.

In the case where a line has multiple addressees and (some of) these are not identifiable, this is annotated using the keyword SEVERAL. This is shown in Example $(6):^{12}$

(6) <CHARACTERS>

$<$ TURN $>$

"That was the first story," said the officer,

$<$ Officer-SEVERAL>

$</$ TURN $>$

\footnotetext{
${ }^{12}$ From Heinrich von Kleist, Improbable Veracities, https://www.gutenberg.org/ (accessed September 30,2018 ).
} 
$<$ NARRATOR $>$

as he took a pinch of snuff and became silent.

$<$ /NARRATOR $>$

$</$ CHARACTERS $>$

Example (6) also shows how a narrative construction within a line is represented as an embedded narrator's discourse (further detailed below).

In contrast, if there are multiple identifiable addressees, these are listed within parentheses as exemplified below: ${ }^{13}$

(7) <CHARACTERS >

$<$ TURN $>$

'Four reales.' 'We want two Anis del Toro.' <Man-Woman>

$</$ TURN $>$

$<$ TURN>

'With water?' <Woman-(Man,Girl)>

$</$ TURN $>$

[...]

</CHARACTERS $>$

A line may also have multiple speakers talking in chorus. This is annotated with a parenthesised expression as in Example (8), analogously with multiple addressees. ${ }^{14}$

(8) <CHARACTERS>

$<$ TURN $>$

'Now watch', said the Zebra and the Giraffe. 'This is the way it's done. One-twothree! And where's your breakfast?' < (Zebra, Giraffe)-Leopard $>$

$</$ TURN $>$

\footnotetext{
${ }^{13}$ From Ernest Hemingway, Hills Like White Elephants, https://www.gutenberg.org/ (accessed September 30, 2018).

${ }^{14}$ From Rudyard Kipling, How the Leopard got his Spots, https://www.gutenberg.org/ (accessed September 30, 2018).
} 
$</$ CHARACTERS $>$

\section{Embeddings}

\section{Characters' discourse embedded in characters' discourse}

Discourse levels can be embedded into each other. In particular, when a character is quoting or recounting a dialogue with someone else, this is represented by embedding that characters' discourse into the present one. This is annotated as an additional opening of CHARACTERS inside the present characters' discourse, as in Example (9). ${ }^{15}$

(9) <CHARACTERS >

$<$ TURN $>$

Did you ever get that thing with the car sorted? Nick said to Evelyn. $<$ NickEvelyn>

$</$ TURN $>$

$<$ TURN $>$

No, Derek won't let me talk to the dealership, she said. He's <Evelyn-Nick>

$<$ CHARACTERS $>$

$<$ TURN $>$

'taking care of it.'<Derek-Evelyn>

$</$ TURN $>$

$<$ CHARACTERS $>$

$</$ TURN $>$

</CHARACTERS $>$

Similarly: ${ }^{16}$

(10) <CHARACTERS>

$<$ TURN $>$

I think your wife is a little on edge today, said Bobbi. <Bobbi-Nick>

\footnotetext{
${ }^{15}$ From Sally Rooney, Conversations with Friends (London: Faber \& Faber, 2017), 138.

${ }^{16}$ From Rooney, Sally, Conversations with Friends (London: Faber \& Faber, 2017), 145.
} 
She was not impressed with my linen-folding technique earlier. Also, $<$ BobbiNick>

$<$ CHARACTERS $>$

$<$ TURN>

she told me she didn't want me 'making any snide remarks about rich people' when Valerie gets here. Quote. <Melissa-Bobbi>

$</$ TURN $>$

$</$ CHARACTERS $>$

$</$ TURN $>$

$</$ CHARACTERS $>$

\section{Narrator's discourse embedded in characters' discourse}

Elements of narrator's discourse may be interspersed, typically in a fragmentary way, inside lines in a characters' discourse without breaking the flow of the dialogue. We represent this by an embedding of the narrator's discourse in the present characters' discourse.

Example (11) illustrates this, where the line " 'It tastes like liquorice,' the girl said" is followed by the narrator's description, "and put the glass down", which is thus embedded within the characters' discourse. ${ }^{17}$

$<$ CHARACTERS $>$

$<$ TURN $>$

'Four reales.' <Man-Girl>

'We want two Anis del Toro.' <Man-Woman>

$</$ TURN $>$

$<$ TURN $>$

'With water?' <Man-Woman>

$</$ TURN $>$

$<$ TURN $>$

\footnotetext{
${ }^{17}$ From Ernest Hemingway, Hills Like White Elephants, https://www.gutenberg.org/ (accessed September 30, 2018).
} 
'Do you want it with water?' <Man-Girl >

$</$ TURN $>$

$<$ TURN $>$

'I don't know', the girl said. 'Is it good with water?' < Girl-Man>

$</$ TURN $>$

$<$ TURN $>$

'It's all right.' <Man-Girl>

$</$ TURN $>$

$<$ TURN $>$

'You want them with water?' asked the woman. <Woman-(Man,Girl?)>”

$</$ TURN $>$

$<$ TURN $>$

'Yes, with water.' <Man-Woman>

$</$ TURN $>$

$<$ TURN $>$

'It tastes like liquorice,' the girl said <Girl-Man>

$<$ NARRATOR $>$

and put the glass down.

$<$ /NARRATOR $>$

$</$ TURN $>$

$<$ TURN $>$

'That's the way with everything.' <Man-Girl>

$</$ TURN $>$

$</$ CHARACTERS $>$

Note that, in accordance with what was said at the end of the introduction section, an embedding is a change of discourse level within another level. This means that if a paragraph begins with dialogues and ends with a narration, the narration is embedded in the character discourse. 


\section{Characters' discourse embedded in narrator's discourse}

We represent indirect discourse - broadly speaking, dialogue rendered narratively - by embedding a characters' discourse into the present narrator's discourse. ${ }^{18}$ Example (12) shows two subsequent characters' discourses being embedded in one narrator's discourse, which is in turn followed by another characters' discourse. ${ }^{19}$

$$
<\text { NARRATOR }>
$$

The car had been sitting in the sun all morning and we had to roll the windows down before we could even get in. Inside it smelled like dust and heated plastic. I sat in the back and Bobbi leaned her little face out the passenger window like a terrier. Nick switched on the radio and Bobbi withdrew her face from the window

$<$ CHARACTERS $>$

$<$ TURN $>$

and said, do you not have a CD player? <Bobbi-Nick>

Can we listen to music? <Bobbi-Nick>

$</$ TURN $>$

$<$ TURN $>$

Nick said: sure, okay. <Nick-Bobbi>

$</$ TURN $>$

$</$ CHARACTERS $>$

Bobbi started looking through the CDs then

$<$ CHARACTERS $>$

$<$ TURN $>$

and saying whether she thought they were his or Melissa's. <Bobbi-Nick> $</$ TURN $>$

$</$ CHARACTERS $>$

$<$ /NARRATOR $>$

$<$ CHARACTERS $>$

\footnotetext{
${ }^{18}$ Manfred Jahn, "N8.4", in Narratology: A guide to the theory of narrative, http://www.uni-koeln. de/ ${ }^{\sim}$ ame02/pppn (accessed September 30, 2018).

${ }^{19}$ From Sally Rooney, Conversations with Friends (London: Faber \& Faber, 2017), 106.
} 
$<$ TURN $>$

Who likes Animal Collective, you or Melissa? she said. <Bobbi-Nick>

$</$ TURN $>$

$<$ TURN $>$

I think we both like them. <Nick-Bobbi>

$</$ TURN $>$

$<$ TURN $>$

But who bought the CD? <Bobbi-Nick>

$</$ TURN $>$

$<$ TURN $>$

I don't remember, he said. You know, we share those things, I don't remember whose is whose. <Nick-Bobbi>

$<$ TURN $>$

$</$ CHARACTERS $>$

In sum, by embedding the characters' discourse in a narrator's discourse, we represent the fact that it's being rendered indirectly through the narration, and not directly as in a (non-embedded) characters' discourse appearing at the (top) level of alternating narrator's and characters' discourses. The reason that we still represent this using an (embedded) characters' discourse is that we want to capture all transmission between the characters, whether it occurs directly at the lowest discourse level or is rendered indirectly at the intermediate level.

\section{Narrator's discourse embedded in narrator's discourse}

A narrator's discourse embedded in a narrator's discourse corresponds to what has been called narrative level, in other words, a story within a story. ${ }^{20}$ Example (13) shows a story imagined by the character within the main story. ${ }^{21}$

(13) $<$ NARRATOR>

\footnotetext{
${ }^{20}$ Genette, Gérard, Narrative Discourse: An Essay in Method (Ithaca, N.Y.: Cornell University Press, 1983), 189; Jahn, Manfred, Narratology: A guide to the theory of narrative, http://www.uni-koeln.de/ ame02/pppn (accessed September 30, 2018).

${ }^{21}$ From Anton Chekov, The Avenger, https://www.gutenberg.org/ (accessed September 30, 2018).
} 
The shopman, swaying gracefully and tripping to and fro on his little feet, still smiling and chattering, displayed before him a heap of revolvers.

The most inviting and impressive of all was the Smith and Wesson's.

Sigaev picked up a pistol of that pattern, gazed blankly at it, and sank into brooding.

$<$ NARRATOR $>$

His imagination pictured how he would blow out their brains, how blood would flow in streams over the rug and the parquet, how the traitress's legs would twitch in her last agony....

$<$ /NARRATOR $>$

But that was not enough for his indignant soul.

The picture of blood, wailing, and horror did not satisfy him.

He must think of something more terrible.

$<$ /NARRATOR $>$

In the Example (14), the narrator addresses the reader and tells something about the main story. 22

(14) <NARRATOR>

I am the man who comes and goes between the bar and the telephone booth.

$<$ NARRATOR-READER $>$

Or, rather: that man is called "I" and you know nothing else about him, just as this station is called only "station" and beyond it there exists nothing except the unanswered signal of a telephone ringing in a dark room of a distant city.

</NARRATOR-READER $>$

I hang up the receiver, I await the rattling flush, down through the metallic throat, I push the glass door again, head toward the cups piled up to dry in a cloud of steam.

$<$ /NARRATOR $>$

\footnotetext{
${ }^{22}$ From Italo Calvino, If on a Winter's Night a Traveler, https://www.gutenberg.org/ (accessed September 30, 2018).
} 


\section{An example of multiple embeddings}

There may be multiple layers of discourse level embeddings. The following example illustrates this. ${ }^{23}$ In Example (15), the narrator's discourse has an embedded characters' discourse, which in turn has an embedded narrator's discourse.

(15) $<$ NARRATOR>

But it wasn't that you woke us.

Oh, no.

$<$ CHARACTERS $>$

$<$ TURN $>$

'They're looking for it; they're drawing the curtain', one might say,

$</$ TURN $>$

$<$ NARRATOR $>$

and so read on a page or two.

$<$ /NARRATOR $>$

$</$ CHARACTERS $>$

[...]

$<$ /NARRATOR $>$

\section{Transmission across levels}

Transmission typically occurs within a single discourse level, but it may also cut across levels, ${ }^{24}$ a phenomenon referred to as metalepsis. ${ }^{25}$ For example, the narrator may explicitly address the (supposed) reader. We annotate this by including the addressee explicitly (here READER) in the discourse level tag $(<$ NARRATOR $>)$ as in Example (16).

(16) <NARRATOR-READER>

\footnotetext{
${ }^{23}$ From Virginia Woolf, A Haunted House, https://www.gutenberg.org/ (accessed September 30, 2018).

${ }^{24}$ Manfred Jahn, Narratology: A guide to the theory of narrative, http://www.uni-koeln.de/ ${ }^{\sim}$ ame02/ pppn (accessed September 30, 2018).

${ }^{25}$ Gérard Genette, Narrative Discourse: An Essay in Method (Ithaca, N.Y.: Cornell University Press, 1983).
} 
You are about to begin reading Italo Calvino's new novel, If on a winter's night a traveler. Relax. Concentrate. Dispel every other thought. Let the world around you fade. Best to close the door; the TV is always on in the next room. [...]

$<$ /NARRATOR-READER $>$

We do not worry about the ontological status of an explicitly addressed reader, for example, whether it is an implied reader or an identifiable physical person.

We distinguish this from the case when a narratee is addressed, typically using second-person pronouns, but no explicit reference to a reader or an act of reading is being made, as in Example (17). ${ }^{26}$

\section{$<$ NARRATOR $>$}

If you really want to hear about it, the first thing you'll probably want to know is where I was born, and what my lousy childhood was like, and how my parents were occupied and all before they had me, and all that David Copperfield kind of crap, but I don't feel like going into it, if you want to know the truth. [...]

$<$ /NARRATOR $>$

Here, it might be tempting to think of "you" as an imagined reader, but it might just as well be an (imagined, third-person) listener to whom Holden Caulfield is telling his story. In the absence of information linking "you" with a reader, we assume the latter possibility. <NARRATOR $>$ is thus the short form for $<$ NARRATOR-NARRATEE $>$.

\section{Scenes}

To represent the basic progression of events in a narrative, we use a notion of scenes, inspired from film. We take a scene to be a coherent set of events at a particular interval in time and place, with a more or less constant set of characters. Furthermore, we take a scene to be the minimal unit in this respect, anticipating that we will later be able to use scenes as primitives in higher-level structures, such as plot. Consider Example (18) about the protagonist of a novel (Frances) who is seeing her father. ${ }^{27}$

After dinner I told my mother I would visit him. She kneaded my shoulder and told me she thought it was a good idea. It's a great idea, she said. Good woman.

\footnotetext{
${ }^{26}$ From J. D. Salinger, The Catcher In The Rye (Boston: Little, Brown and Company, 1951), where this is a frequent phenomenon.

${ }^{27}$ From Sally Rooney, Conversations with Friends (London: Faber \& Faber, 2017), 51-52.
} 
I walked through town with my hands in my jacket pockets. The sun was setting and I wondered what would be on television. I could feel a headache developing, like it was coming down from the sky directly into my brain. I tried stamping my feet as loudly as I could to distract myself from bad thoughts, but people gave me curious looks and I felt cowed. I knew that was weak of me. Bobbi was never cowed by strangers.

My father lived in a little terraced house near the petrol station. I rang the doorbell and put my hands back in my pockets. Nothing happened. I rang again and then I tried the handle, which felt greasy. The door opened up and I stepped in.

Dad? I said. Hello?

[...]

I'm off, I said.

You're away, are you?

That bin needs taking out.

See you again, my father said.

Our basic criterion for dividing a narrative into scenes is to think about it in terms of a faithful rendering as a film or a play. In the example above, we would obtain three scenes: The first one includes Frances and her mother at her mother's place talking to each other, the second is Frances's walking on her own to her father's place, and the third one includes Frances and her father's meeting at her father's place (further developed in the story). We would thus annotate the passage above as in Example (19).

(19) $<$ SCENE $>$

$<$ NARRATOR $>$

After dinner I told my mother I would visit him. She kneaded my shoulder

$<$ CHARACTERS $>$

$<$ TURN $>$

and told me she thought it was a good idea. <Mother-Frances $>$

It's a great idea, she said. <Mother-Frances $>$

Good woman. <Mother-Frances>

$</$ TURN $>$ 
$</$ CHARACTERS $>$

$<$ NARRATOR $>$

$</$ SCENE $>$

$<$ SCENE $>$

$<$ NARRATOR $>$

I walked through town with my hands in my jacket pockets. The sun was setting and I wondered what would be on television. I could feel a headache developing, like it was coming down from the sky directly into my brain. I tried stamping my feet as loudly as I could to distract myself from bad thoughts, but people gave me curious looks and I felt cowed. I knew that was weak of me. Bobbi was never cowed by strangers.

$<$ /NARRATOR $>$

$</$ SCENE $>$

$<$ SCENE $>$

$<$ NARRATOR $>$

My father lived in a little terraced house near the petrol station. I rang the doorbell and put my hands back in my pockets. Nothing happened. I rang again and then I tried the handle, which felt greasy. The door opened up and I stepped in.

$<$ /NARRATOR $>$

$<$ CHARACTERS $>$

$<$ TURN $>$

Dad? I said. Hello? < Frances-Dad > [...]

$</$ TURN $>$

$</$ CHARACTERS $>$

[...]

$<$ CHARACTERS $>$

$<$ TURN $>$

I'm off, I said. <Frances-Dad>

You're away, are you? <Dad-Frances $>$ 
That bin needs taking out. <Frances-Dad $>$

See you again, my father said. $<$ Dad-Frances $>$

$</$ TURN $>$

$</$ CHARACTERS $>$

$</$ SCENE $>$

In this example, there are three scenes. The first scene covers the first $<$ NARRATOR $>$ and $<$ CHARACTERS $>$ elements. The second scene covers the second $<$ NARRATOR $>$ element, and the third scene covers the third $<$ NARRATOR $>$ element and the second and third $<$ CHARACTERS $>$ elements.

\section{Narrative situation}

This section describes two notions related to the position and perspective of the narrator. We refer collectively to these as narrative situation. ${ }^{28}$

\section{Voice}

The notion of voice concerns the narrator's relationship to the story, and more specifically whether the narrator is ever present in the story or not. ${ }^{29}$ If the narrator appears in the story at some point, we say that we have a homodiegetic narrative. Such narrators usually refer to themselves in the first person, but there are exceptions to this, such as Caesar's De Bello Gallico in which the narrator refers to himself in the third person. In contrast, if the narrator is never present in the story, we say that we have a heterodiegetic narrative. Such narrators usually refer to themselves in the third person, but again there are exceptions.

We annotate this binary distinction using $<$ VOICE_1 $1>$ for a homodiegetic narrator and $<$ VOICE_3 $>$ for a heterodiegetic narrator, with corresponding closing tags $</$ VOICE_1 $>$ and $</$ VOICE_3 $>$, respectively.

\section{Focalisation}

We take focalisation to correspond to the perspective from which the narrative is seen, and specifically how much information the narrator has access to; alterna-

\footnotetext{
${ }^{28}$ Inspired by Gérard Genette, Narrative Discourse: An Essay in Method (Ithaca, N.Y.: Cornell University Press, 1983), 188, but we do not use the term in the full meaning developed there.

${ }^{29}$ Gérard Genette, Narrative Discourse: An Essay in Method (Ithaca, N.Y.: Cornell University Press, 1983), Chapter 5.
} 
tively, in what ways this information is restricted. ${ }^{30}$ We distinguish the following types:

- Zero or unrestricted The story is narrated from a fully unrestricted or omniscient perspective. This often involves helicopter views of the story that no single character would be capable of, but it could also involve taking the perspectives or looking into the souls of the individual characters. The narrator knows more than any of the characters, symbolised by Narrator $>$ Character. $^{31}$ We annotate this as $<$ FOC_UNR $>$ with a corresponding closing tag $<$ /FOC_UNR $>$.

- Internal The story is narrated from the inside perspective of a character in the story, limited by the perception and feelings of that character. The narrator knows only as much as this character, symbolised by Narrator $=$ Character. ${ }^{32}$ We annotate this as $<$ FOC_INT $>$ with a corresponding closing tag $<$ /FOC_INT $>$.

- External The story is narrated from a perspective outside of the characters in the story, like using a camera, but without an omniscient perspective, as in $<$ FOC_UNR $>$. Typically, the main components of such narratives are dialogues and narrations in the form of neutral descriptions of events. The narrator knows less than any of the characters, symbolised by Narrator $<$ Character. ${ }^{33}$ We annotate this as $<$ FOC_EXT $>$ with a corresponding closing tag $</$ FOC_EXT $>$.

\section{Definitions}

We end with a list of definitions of some of our central terminology.

Author's discourse: The highest level of transmission in a narrative, from the author to a (typically) imagined, but explicitly referred reader of a story. Consists of text.

\footnotetext{
${ }^{30}$ Gérard Genette, Narrative Discourse: An Essay in Method (Ithaca, N.Y.: Cornell University Press, 1983), 189.

${ }^{31}$ As put by Tzvetan Todorov, "Les catégories du récit littéraire", in Communications, 8 (1966): 125-151, cited in Gérard Genette, Narrative Discourse: An Essay in Method (Ithaca, N.Y.: Cornell University Press, 1983), 188.

${ }^{32}$ As put by Tzvetan Todorov, "Les catégories du récit littéraire", in Communications, 8 (1966): 125151.

${ }^{33}$ As put by Tzvetan Todorov, "Les catégories du récit littéraire", in Communications, 8 (1966): 125151.
} 
Characters' discourse: The lowest level of transmission in a narrative, from character to character. Consists of one or more turns.

Dialogue: The text corresponding to a characters' discourse. This is not limited to spoken dialogue, but could also be soliloquy, interior monologue, thoughts, etc.

Layer: This refers to the overall annotation, which is ordered by an inclusion relation in four hierarchical layers.

Level: This refers to the type of narrative transmission in the fourth annotation layer. We distinguish between the highest level (author's discourse), the intermediate level (narrator's discourse) and the lowest level (characters' discourse).

Narration: The text corresponding to a narrator's discourse.

Narrator: The teller of the narrative; the person who articulates ("speaks") the narrative. $^{34}$

Narrator's discourse: The intermediate level of transmission in a narrative, from narrator to narratee. Consists of text.

Narrative: Anything that tells or presents a story. ${ }^{35}$

Narrative situation: A collective name for voice and focalisation. ${ }^{36}$

Story: A sequence of events involving characters. ${ }^{37}$

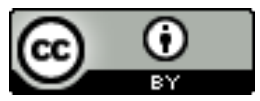

Unless otherwise specified, all work in this journal is licensed under a Creative Commons Attribution 4.0 International License.

\footnotetext{
${ }^{34}$ Quoted from Manfred Jahn, "N1.2", in Narratology: A guide to the theory of narrative, http:// www.uni-koeln.de/ ${ }^{\sim}$ ame02/pppn (accessed September 30, 2018).

${ }^{35}$ Quoted from Manfred Jahn, "N1.2", in Narratology: A guide to the theory of narrative, http:// www.uni-koeln.de/ ${ }^{\sim}$ ame02/pppn (accessed September 30, 2018).

${ }^{36}$ Note that our use of the term does not capture the full meaning of that used by Gérard Genette, Narrative Discourse: An Essay in Method (Ithaca, N.Y.: Cornell University Press, 1983), 188.

${ }^{37}$ Quoted from Manfred Jahn, "N1.2", in Narratology: A guide to the theory of narrative, http:// www.uni-koeln.de/ ${ }^{\sim}$ ame02/pppn (accessed September 30, 2018).
} 